\title{
Favorable outcomes with laparoscopic surgery for rectal cancer
}

\author{
M. H. G. M. van der Pas $\cdot$ E. A. te Velde • \\ M. A. Cuesta $\cdot$ H. J. Bonjer
}

Received: 17 June 2010/Accepted: 24 July 2010/Published online: 22 December 2010

(C) The Author(s) 2010. This article is published with open access at Springerlink.com

Liakakos et al. [1] concluded from a retrospective series of 1,057 selected patients studied by Miyajima et al. [2] that laparoscopic surgery for rectal cancer is safe. Although cohort studies have shown safety, the most important outcomes such as disease-free survival and the recurrence rate need to be demonstrated in prospective randomized controlled trials before laparoscopic surgery is accepted as the standard approach.

Laparoscopic resection of colonic cancer is proved to be safe, with no difference in long-term oncologic outcome compared with open surgery [3-5]. However, long-term outcome data after laparoscopic surgery for rectal cancer still are not available.

Only 5 years ago, the first study investigating the quality of the mesorectal dissection with 25 patients was published [6]. The first randomization was done in the conventional versus laparoscopically-assisted surgery in Colorectal Cancer (CLASICC) trial with 253 patients treated with laparoscopic surgery. The conversion rate at the beginning of the trial was $34 \%$, which decreased to $16 \%$ during the sixth year of the study [5]. This high conversion rate in a relatively small study group was due the experience curve effect.

Miyajima et al. [2] concluded that laparoscopy is feasible and safe for selected patients with rectal cancer, with favorable short- and mid-term outcomes after a mean follow-up period of 30 months. This retrospective study, not intended to be a comparison between open and laparoscopic surgery, was reported without long-term outcome

M. H. G. M. van der Pas - E. A. te Velde .

M. A. Cuesta $\cdot$ H. J. Bonjer $(\square)$

Department of Surgery, VU University Medical Centre,

De Boelelaan 1117, 1007 Amsterdam, The Netherlands

e-mail: j.bonjer@vumc.nl data. Therefore, as stated by Liakakos et al. [1], more data are needed from randomized controlled trials, if feasible, to support the hypothesis of better oncologic outcomes for closed rather than open surgery for rectal cancer.

Currently, several multicenter randomized controlled trials comparing laparoscopic and open surgery for rectal cancer are registered (Clinicaltrials.gov) and recruiting patients, including the laparoscopic-assisted resection or open resection in treating patients with Stage IIA, Stage IIIA, or Stage IIIB rectal cancer (NCT00726622) trial by the American College of Surgeons (estimated primary completion date, August 2010) and the Phase II trial to evaluate laparoscopic surgery for Stage 0/1 rectal carcinoma (Lap RC), NCT00635466 (estimated study completion date, 2016).

In addition, the comparing laparoscopic and open surgery for rectal cancer (COLOR II) trial (NCT00297791) will fulfil the profound need for a well-designed and performed randomized trial. Recently, this COLOR II trial finished randomization of 1,100 patients. The short-term results will be presented by the colorectal cancer laparoscopic or open resection study group on a short notice.

The primary end point of the COLOR II trial is the locoregional recurrence rate 3 years postoperatively. Until these data become available, we believe that open total mesorectal excision must be regarded as the gold standard treatment for rectal cancer.

Disclosures M. H. G. M. van der Pas, E. A. te Velde, M. A. Cuesta, and H. J. Bonjer have no conflicts of interest or financial ties to disclose.

Open Access This article is distributed under the terms of the Creative Commons Attribution Noncommercial License which permits any noncommercial use, distribution, and reproduction in any medium, provided the original author(s) and source are credited. 


\section{References}

1. Liakakos T, Kopanakis K, Schizas D (2010) Favorable outcomes with laparoscopic surgery for rectal cancer. Surg Endosc 24:1217-1218

2. Miyajima N, Fukunaga M, Hasegawa H, Tanaka J, Okuda J, Watanabe M (2009) Results of a multicenter study of 1,057 cases of rectal cancer treated by laparoscopic surgery. Surg Endosc 23:113-118

3. The Clinical Outcomes of Surgical Therapy Study Group (2004) A comparison of laparoscopically assisted and open colectomy for colon cancer. N Engl J Med 350:2050-2059

4. Buunen M, Veldkamp R, Hop WC, Kuhry E, Jeekel J, Haglind E, Pahlman L, Cuesta MA, Msika S, Morino M, Lacy A, Bonjer HJ
(2009) Survival after laparoscopic surgery versus open surgery for colon cancer: long-term outcome of a randomised clinical trial. Lancet Oncol 10:44-52

5. Jayne DG, Guillou PJ, Thorpe H, Quirke P, Copeland J, Smith AM, Heath RM, Brown JM (2007) Randomized trial of laparoscopic-assisted resection of colorectal carcinoma: 3-year results of the UK MRC CLASICC trial group. J Clin Oncol 25:3061-3068

6. Breukink SO, Grond AJ, Pierie JP, Hoff C, Wiggers T, Meijerink WJ (2005) Laparoscopic vs open total mesorectal excision for rectal cancer: an evaluation of the mesorectum's macroscopic quality. Surg Endosc 19:307-310 